\title{
Transportins 1 and 2 are redundant nuclear import factors for hnRNP A1 and HuR
}

\author{
ANA REBANE, ALAR AAB, and JOAN A. STEITZ \\ Department of Molecular Biophysics and Biochemistry, Howard Hughes Medical Institute, Yale University School of Medicine, \\ New Haven, Connecticut 06536, USA
}

\begin{abstract}
Several mRNA-binding proteins, including hnRNP A1 and HuR, contain bidirectional transport signals that mediate both their nuclear import and export. Previously, Transportin 1 (Trn1) was identified as a mediator of hnRNP A1 import, whereas the closely related protein Transportin 2 ( $\operatorname{Trn} 2)$ was shown to interact with HuR. Here we have investigated the subfamily of transportins that consists of Trn1 (or Kap $\beta 2 A$ ) and two alternatively spliced Trn2 isoforms (Trn2a and Trn2b), also called Trn2 and Kap $\beta 2 B$. The sequence differences among these proteins could alter either their cargo specificity or their response to RanGTP and thus their function as import or export receptors. Using in vitro binding assays, we show that hnRNP A1 preferentially binds Trn1 and Trn2b versus Trn2a. HuR interacts with all three transportins, as well as weakly with Imp $\beta$. The hnRNP A1 and HuR shuttling domains, called M9 and HNS, respectively, are sufficient for these interactions. Despite small differences in the binding of HuR and hnRNP A1 to the three transportins, in vitro interaction studies performed in the presence and absence of RanQ69LGTP indicate that all three transportins most likely act as import factors for HuR and hnRNP A1. In digitonin-permeabilized HeLa cells, both M9 and HNS peptides compete for the import of recombinant hnRNP A1 and HuR, indicating that HuR and hnRNP A1 import pathways are at least partially overlapping. Possible nucleocytoplasmic shuttling mechanisms for hnRNP A1 and HuR are discussed.
\end{abstract}

Keywords: nuclear export; mRNA export; mRNA stability; ARE; ELAV

\section{INTRODUCTION}

The majority of characterized nucleocytoplasmic transport pathways involve importin $\beta$ (Imp $\beta$ )-type receptors or karyopherins (for review, see Mattaj and Englmeier 1998; Görlich and Kutay 1999; Chook and Blobel 2001). There are $>20$ Imp $\beta$-like transport receptors in mammalian cells that can be subclassified as importins or exportins. However, both types of Imp $\beta$-like receptors are similar in size $(90$ $130 \mathrm{kD}$ ) and secondary structure, and they all interact with the small GTPase Ran (for review, see Chook and Blobel 2001). Ran appears to play a central role in both providing energy for and determining the directionality of nucleocytoplasmic transport (Izaurralde et al. 1997b; Görlich et al. 1996). Ran is predominantly GTP-bound in the nucleus, whereas it is in a GDP-bound form in the cytoplasm. Consequently, importins load their cargoes at low RanGTP concentration in the cytoplasm, translocate into the nucleus,

Reprint requests to: Joan A. Steitz, Room 136, Howard Hughes Medical Institute, Yale University School of Medicine, New Haven, CT 06536, USA; e-mail: joan.steitz@yale.edu; fax: (203) 624-8213.

Article and publication are at http://www.rnajournal.org/cgi/doi/ 10.1261/rna.5224304. and release them upon binding of RanGTP. Exportins bind their export substrates and RanGTP simultaneously in the nucleus; trimeric RanGTP-exportin-cargo complexes are then carried to the cytoplasm, where they dissociate upon GTP hydrolysis (for review, see Mattaj and Englmeier 1998; Görlich and Kutay 1999; Kuersten et al. 2001).

Importins and exportins recognize their cargoes via protein- or RNA-based sequence elements termed nuclear localization signals (NLS) and nuclear export signals (NES; for review, see Mattaj and Englmeier 1998; Nakielny and Dreyfuss 1999). Normally, NLS and NES signals, as well as their cognate import and export receptors, are distinct. However, several mRNA-binding proteins contain nucleocytoplasmic shuttling sequences that appear to mediate both nuclear import and export. The best characterized of these is hnRNP Al, an abundant nuclear hnRNP protein that contains a 38-amino-acid-long shuttling signal termed M9 (Fig. 1A; Michael et al. 1995; Siomi and Dreyfuss 1995).

To date, only one transport receptor, called Trn1 or karyopherin $\beta 2 \mathrm{~A}$ (Kap $\beta 2 \mathrm{~A})$, has been shown to bind the M9 signal and import hnRNP A1 protein into the nucleus (Nakielny et al. 1996; Pollard et al. 1996; Bonifaci et al. 1997; Fridell et al. 1997). In addition to hnRNP A1, Trn1 is 

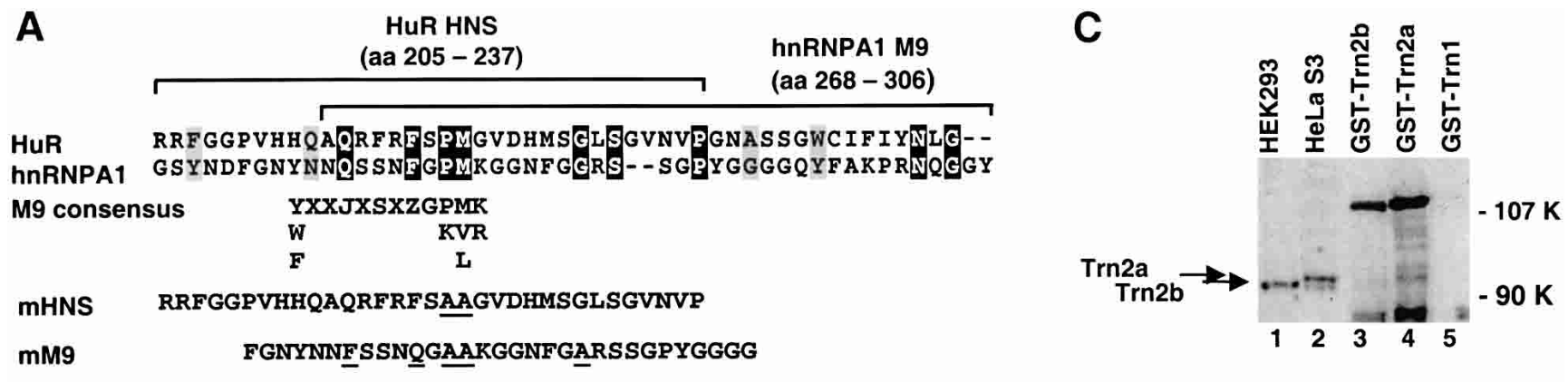

B
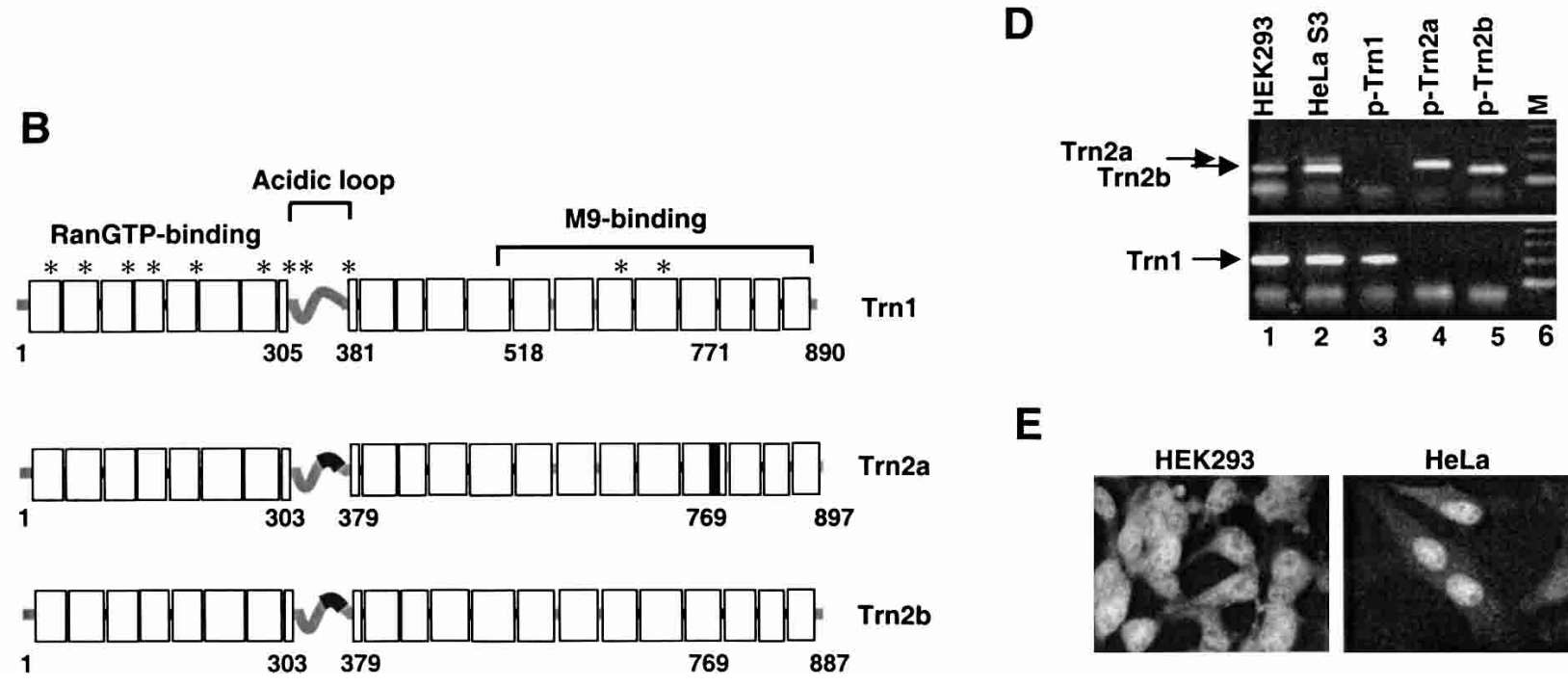

$\mathbf{E}$
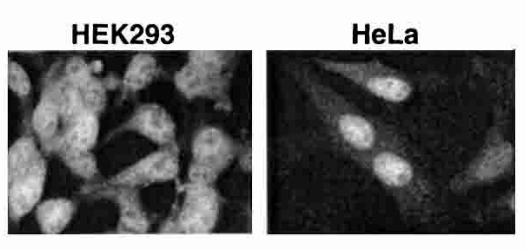

FIGURE 1. Comparison of HNS and M9 sequences, schematic representation of the domain structure of transportins, and expression of transportins in HeLa and HEK 293 cells. (A) Amino acid sequence alignment of HNS from human HuR (Fan and Steitz 1998a), M9 from human hnRNP A1 (Michael et al. 1995), and the M9 consensus (Bogerd et al. 1999). Amino acids identical between HNS and M9 are indicated by black boxes; similar amino acids are boxed in gray. In the consensus sequence, (J) hydrophilic amino acids; ( $\mathrm{Z}$ ) hydrophobic amino acids; (X) any residue. mHNS is the mutant HNS sequence encoded by the GST-mHNS construct (Fig. 3B), and mM9 is the sequence of the mutant M9 peptide used as a control in the competition experiments (Fig. 4B). Altered residues in mHNS and mM9 are underlined. (B) Schematic representation of the domain structure of $\operatorname{Trn} 1$ and its close homologs $\operatorname{Trn} 2 \mathrm{a}$ and $\operatorname{Trn} 2 \mathrm{~b}$. The Trn 1 protein consists of $20 \alpha$-helical HEAT repeats (white boxes); a less-structured acidic loop (amino acids 305-381) is designated with a gray curved line, RanGTP contacts (Chook and Blobel 1999; Chook et al. 2002) with asterisks; and the C-terminal part (amino acids 518-890) of Trn1 that is sufficient for M9 binding (Pollard et al. 1996; Fridell et al. 1997) is indicated above. The most variable sequences of Trn2a and Trn2b are designated with black boxes. (C) Western blot analysis of Trn2a and Trn2b proteins, in which $\sim 20 \mu \mathrm{g}$ of HeLa S3 and HEK293 whole-cell extracts (lanes 1-2) and $5 \mathrm{ng}$ of recombinant GST-tagged Trn2b, Trn2a, and Trn1 (lanes 3-5) were analyzed using anti-Trn2 serum. (D) Expression analysis of transportins by RT-PCR. (Lanes 1-5) PCR products (243 bp) using Trn1-specific primers; (lanes 6-10) show PCR products (194 bp for Trn2a and $164 \mathrm{bp}$ for Trn2b) using Trn2-specific primers. PCR was performed on cDNA prepared from HEK293 (lane 1) or HeLa S3 cells (lane 2). Control PCR reactions with both primer pairs were carried out on plasmids containing Trn1 (lane 3), Trn2a (lane 4), or Trn2b (lanes 5) cDNA. (Lane 6) A 123-bp marker (Invitrogen). (E) Cellular localization of Trn2 in HEK293 and HeLa cells.

the import receptor for hnRNP F (Siomi et al. 1997), for the mRNA export factor TAP (Truant et al. 1999; Bachi et al. 2000), and for ribosomal proteins such as rpL23a, rpS7, and rpL5 (Jäkel and Görlich 1998). The ribosomal proteins and TAP bind Trn 1 via basic lysine- and arginine-rich sequences that functionally differ from M9 because these domains exhibit only NLS but not NES activity (Jäkel and Görlich 1998; Truant et al. 1999; Bachi et al. 2000).

In the course of isolating the full-length human Trn1 cDNA, an $84 \%$ identical protein $\operatorname{Trn} 2$ was characterized (Siomi et al. 1997). Despite high similarity to Trn1, Trn2 did not exhibit the same high affinity in vitro for a set of test nucleic-acid-binding proteins, including hnRNP Al. In- stead, HuR, another mRNA-binding protein, was shown to bind to Trn2 via its shuttling signal HNS (Gallouzi and Steitz 2001). Accordingly, the HNS sequence partially matches the M9 sequence of hnRNP A1 and the M9 consensus sequence as defined by a combination of mutational randomization followed by selection for Trn1 (Fig. 1A; Fan and Steitz 1998a; Bogerd et al. 1999). Like hnRNP A1, HuR is a nucleocytoplasmic shuttling protein (Fan and Steitz 1998b). HuR is known to stabilize unstable mRNAs that contain AU-rich sequences (AREs) within their 3 '-untranslated region ( $3^{\prime}$-UTR); most likely the ability of HuR to relocalize to the cytoplasm is important for this function (for review, see Brennan and Steitz 2001). As shuttling and 
mRNA-binding proteins, hnRNP Al and HuR have been suggested also to function in mRNA export (Izaurralde et al. 1997a; Gallouzi and Steitz 2001). A more recently described variant of $\operatorname{Trn} 2$ termed Kap $\beta 2 \mathrm{~B}$ has been proposed to participate in mRNA export as well, but in cooperation with the main mRNA export factor TAP (Shamsher et al. 2002).

The data presented here support the argument that Trn1 and $\operatorname{Trn} 2$ are redundant import factors for hnRNP A1 and HuR. First, we confirmed that the two previously reported Trn2 protein sequences (Siomi et al. 1997; Shamsher et al. 2002) represent two alternatively spliced isoforms, which we now designate $\operatorname{Trn} 2 \mathrm{a}$ and $\operatorname{Trn} 2 \mathrm{~b}$. Using in vitro binding assays, we show that hnRNP A1 prefers to bind to Trn 1 and $\operatorname{Trn} 2 \mathrm{~b}$ versus $\operatorname{Trn} 2 \mathrm{a}$, whereas HuR interacts with all three transportins. The hnRNP Al and HuR shuttling domains, M9 and HNS, respectively, are sufficient for these interactions. Further in vitro binding assays show that the presence of RanQ69LGTP decreases the affinity of hnRNP A1 and HuR for the transportins, indicating that all three transportins are most likely import factors for HuR and hnRNP A1. Competition experiments using M9 and HNS peptides in digitonin-permeabilized HeLa cells confirm that HuR and hnRNP Al at least partially share the same import pathway(s).

\section{RESULTS AND DISCUSSION}

\section{Transportin 2 is expressed in two spliced forms}

To understand better the role of Trn1 and Trn2 in nucleocytoplasmic transport, we first compared the two separately published human Trn2 cDNA sequences, Trn2 (AF019039; Siomi et al. 1997) and Kap B2B (AF007748; Shamsher et al. 2002). They possess identical coding potential except for a 30-nt insertion in the AF019039 sequence compared with AF007748 within the $3^{\prime}$ part of the cDNA. A search for the two Trn 2 mRNA sequences in human and mouse expressed sequence tag (EST) databases revealed two human and four mouse ESTs corresponding to AF019039 and eight human and five mouse ESTs corresponding to AF007748. Further comparison with sequences present in the EMBL/GenBank/ DDBJ nonredundant database identified a putative human Trn2 gene sequence with location 19p13.2 (http://www. ncbi.nlm.nih.gov/LocusLink). Map Viewer (http://www.ncbi. nlm.nih.gov/mapview/maps) revealed that AF019039 and AF007748 differ only in what appears to be an alternatively spliced exon 20 that is preceded by two different $3^{\prime}$ splice sites (separated by $30 \mathrm{nt}$ ) and followed by a single $5^{\prime}$ splice site consensus sequence. We termed the two corresponding Trn2 proteins Trn2a (AF019039) and Trn2b (AF007748). Schematics of the domain structure of the closely related Trn1 protein, derived from its crystal structure (Chook and Blobel 1999; Chook et al. 2002), and the predicted domains of the two Trn2 proteins are presented in Figure 1B.
Next, we examined the expression of the two Trn2 isoforms in human cell lines. A rabbit polyclonal antibody recognizing both $\operatorname{Trn} 2 \mathrm{a}$ and $\operatorname{Trn} 2 \mathrm{~b}$ was raised against a peptide (amino acids 344-361) corresponding to the sequence with the least correspondence to Trn1 located within the acidic loop (Fig. 1B; Chook et al. 2002). As shown in Figure 1C, the anti-Trn2 serum specifically recognizes and can distinguish between recombinant Trn2a and $\operatorname{Trn} 2 \mathrm{~b}$ versus $\operatorname{Trn} 1$ (lanes $3-5$ ). Interestingly, only the Trn2b protein is expressed in human embryonic kidney (HEK293) cells (lane 1), whereas both $\operatorname{Trn} 2 \mathrm{a}$ and $\operatorname{Trn} 2 \mathrm{~b}$ are detected in HeLa S3 cells (lane 2). These expression patterns were confirmed by RT-PCR analyses (Fig. 1D, top panel). However, in contrast to the Western results, RT-PCR with $\operatorname{Trn} 2$-specific primers indicated higher expression of $\operatorname{Trn} 2 \mathrm{~b}$ than Trn2a in HeLa S3 cells (Fig. 1D, lane 2), probably caused by preferential amplification of the shorter DNA. RT-PCR with Trn1-specific primers confirmed that Trn1 is expressed in both the studied cell lines (Fig. 1D, bottom panel).

To verify the cellular localization of Trn2 in HEK293 and HeLa cells, immunofluorescence using affinity-purified anti-Trn2 antibodies was carried out. As previously shown for Trn1 (Siomi et al. 1997) and Trn2 (Gallouzi and Steitz 2001) in HeLa cells, the Trn2 protein is localized both in the nucleus and the cytoplasm of HEK293 cells (Fig. 1E, left panel). However, Trn2 appears more abundant in the cytoplasm of HEK293 cells compared with HeLa cells (Fig. 1E, cf. left and right panels).

In conclusion, database analyses, expression studies, and previous reports (Siomi et al. 1997; Shamsher et al. 2002) demonstrate that the two proteins, $\operatorname{Trn} 2 \mathrm{a}$ and $\operatorname{Trn} 2 \mathrm{~b}$, are most probably the products of alternatively spliced mRNAs encoded by a single Trn 2 gene located on human Chromosome 19.

\section{Trn1 and Trn2 interact with both hnRNP A1 and HuR in HeLa nuclear extract}

Previously, it was reported that Trn1 binds a distinct set of cargoes compared with Trn2a (Siomi et al. 1997; Gallouzi and Steitz 2001). However, the lack of 10 extra amino acids within the C-terminal part of Trn2b generates a very similar sequence to $\operatorname{Trn} 1$ (89\% identical and $94 \%$ similar between amino acids $493-890$ of $\operatorname{Trn} 1$ ) in the region expected to bind cargo. This indicated that Trn 1 and Trn $2 b$ might exhibit similar specificity for cargo proteins.

To test this hypothesis, we first examined HuR and hnRNP A1 interactions with transportins in in vitro pulldown assays. As shown in Figure 2, hnRNP A1 in nuclear extract binds preferentially to GST-tagged $\operatorname{Trn} 1$ and $\operatorname{Trn} 2 \mathrm{~b}$ (lanes 1 and 3, top panel) relative to GST-Trn2a (lane 2, top panel), and not to GST-Imp $\beta$ (lane 4 , top panel). HuR in nuclear extract interacts more strongly with both forms of GST-tagged Trn2 (lanes 2 and 3, middle panel) than with 


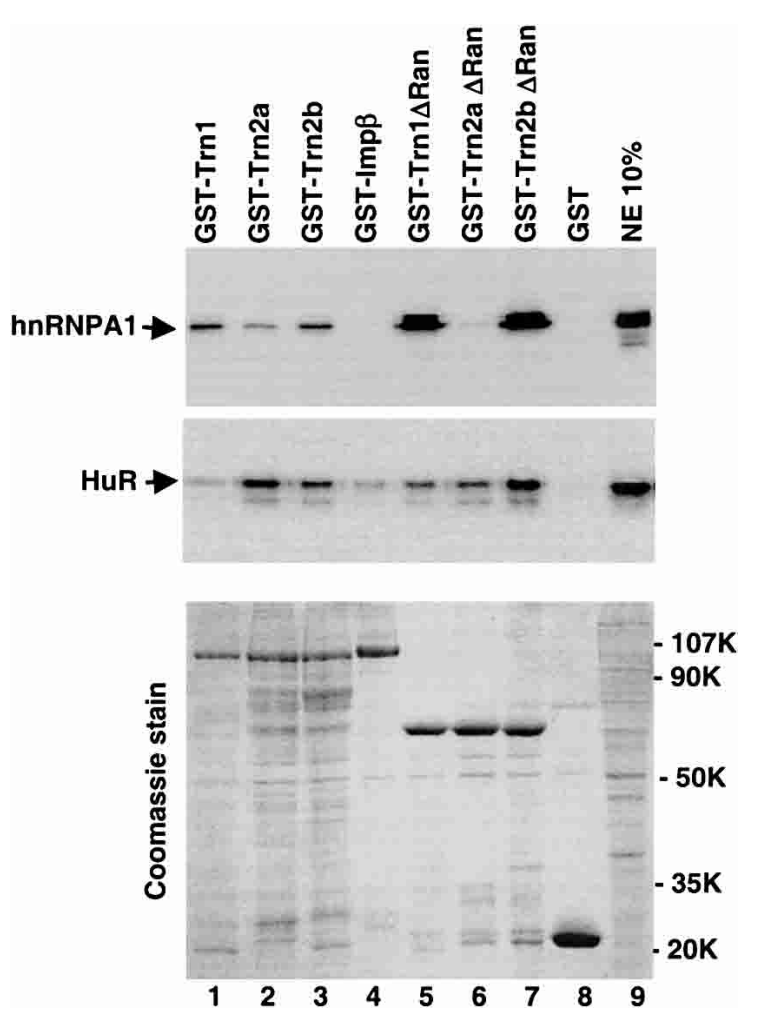

FIGURE 2. hnRNP Al and HuR interact with transportins in HeLa nuclear extract. Glutathione Sepharose beads were precoated with GST fusions of transportins (lanes 1-3), Imp $\beta$ (lane 4), mutant transportins lacking the RanGTP-binding domain ( $\Delta$ Ran, lanes $5-7)$, or with GST alone (lane 8 ) and incubated with HeLa nuclear extract. Bound proteins were analyzed by Western blotting using monoclonal anti-hnRNP Al or anti-HuR antibodies. One-fifth of each binding reaction was analyzed on SDS-PAGE followed by Coomassie staining to confirm efficient binding of GST-tagged proteins to the glutathione beads (bottom panel). Lane 9 contains $10 \%$ of the HeLa nuclear extract used in adjacent lanes.

Trn 1 and Imp $\beta$ (lanes 1 and 4, middle panel). To confirm comparable binding of the GST-tagged proteins to the glutathione beads, $1 / 5$ of each binding reaction was analyzed by SDS-PAGE followed by Coomassie staining (Fig. 2, bottom panel).

It was reported earlier that the C-terminal region of Trn1 (amino acids 518-890, Pollard et al. 1996; amino acids 547890, Fridell et al. 1997) is sufficient for binding hnRNP A1 (see also Fig. 1B). Likewise, the GST pull-down experiments with nuclear extract showed that the $\mathrm{C}$ terminus of $\operatorname{Trn} 1$ (amino acids 494-890), as well as of Trn2b (amino acids 491-887), is sufficient for binding hnRNP A1 (Fig. 2, lanes 5-7). Thus, as reported by Siomi et al. (1997), 10 extra amino acids present in the Trn2a C-terminal region appear to hinder hnRNP Al binding. In contrast to hnRNP Al, HuR exhibited reduced binding to GST fusions of C-terminal portions of transportins (Fig. 2, lanes 5-7, middle panel). This indicates that either HuR and hnRNP A1 interact with slightly different sites in the transportins or that the conformations of the $\operatorname{Trn} 2 \mathrm{a}$, $\operatorname{Trn} 2 \mathrm{~b}$, and $\operatorname{Trn} 1 \mathrm{C}$-termi- nal fragments are not optimal for HuR binding. Alternatively, because our in vitro binding assays were performed in nuclear extract, we cannot exclude the possibility that other proteins mediate the interactions detected between the transport receptors and hnRNP Al or HuR.

In summary, in vitro binding experiments demonstrate that hnRNP A1 in nuclear extract interacts with GST-tagged Trn 1 and Trn2b and less efficiently with Trn2a; HuR preferentially binds to $\operatorname{Trn} 2 \mathrm{a}$ and $\operatorname{Trn} 2 \mathrm{~b}$ relative to $\operatorname{Trn} 1$ and Imp $\beta$. The previous data indicating that HuR binds only Trn2a and not Trn1 (Gallouzi and Steitz 2001) might have resulted if recombinant GST-Trn1 was not prepared and stored carefully, because we have observed that GST-Trn1 loses its ability to bind hnRNP Al and HuR after a few freeze-thaw cycles, whereas GST-Trn2a and GST-Trn2b remain active in binding.

\section{RanGTP dissociates transportin complexes with HuR or hnRNP A1}

The crystal structure of the Trn1-RanGppNHp complex revealed that $\operatorname{Trn} 1$ consists of $20 \alpha$-helical HEAT repeats (Chook and Blobel 1999; Chook et al. 2002). Within HEAT repeat 8 (amino acids 305-381), there exists a less structured acidic loop (Fig.1B) that contacts RanGTP, as well as the C-terminal cargo-binding domain (amino acids 518890). RanGTP hydrolysis and accompanying Ran dissociation introduce conformational changes into the protein that have been suggested to be transmitted by the acidic loop to the cargo-binding region: Trn1 with a mutated acidic loop (Fig. 1B, amino acids 341-362) can simultaneously bind both the cargo and RanGTP, but is unable to undergo Ranmediated substrate dissociation (Chook et al. 2002). Intriguingly, the most variable sequence between $\operatorname{Trn} 1$ and both forms of Trn2 is within the acidic loop (amino acids 344-362 of Trn1). These observations indicated that there could be differences in the response of $\operatorname{Trn} 1$ and $\operatorname{Trn} 2$ to RanGTP binding. Indeed, Trn1 had previously been shown to function as an import factor for the TAP protein (Truant et al. 1999; Bachi et al. 2000), whereas Trn2b was suggested to be an export factor for TAP (Shamsher et al. 2002).

To ask whether hnRNP Al or HuR interactions with transportins are influenced by RanGTP, in vitro binding experiments in the presence and absence of a GTPase deficient mutant (Bischoff et al. 1994) of Ran loaded with GTP (RanQ69LGTP) were performed. Figure 3A reveals that the strong interactions between $\left[{ }^{35} \mathrm{~S}\right]$-methionine-labeled Trn1 and GST-hnRNP A1 or GST-HuR (lanes 1-4, Trn1 panel), as well as those between $\left[{ }^{35} \mathrm{~S}\right] \operatorname{Trn} 2 \mathrm{a}$ and GSTHuR (lanes 3-4, Trn2a panel) were significantly diminished (about sevenfold) in the presence of RanQ69LGTP. The binding of $\left[{ }^{35} \mathrm{~S}\right] \mathrm{Trn} 2 \mathrm{~b}$ to GST-hnRNP A1 or GST-HuR was less dramatically, but reproducibly lowered (about twofold) by RanQ69LGTP (lanes 1-4, Trn2b panel). Even the very weak interactions between $\left[{ }^{35} \mathrm{~S}\right] \operatorname{Trn} 2 \mathrm{a}$ and GST-hnRNP A1 
A

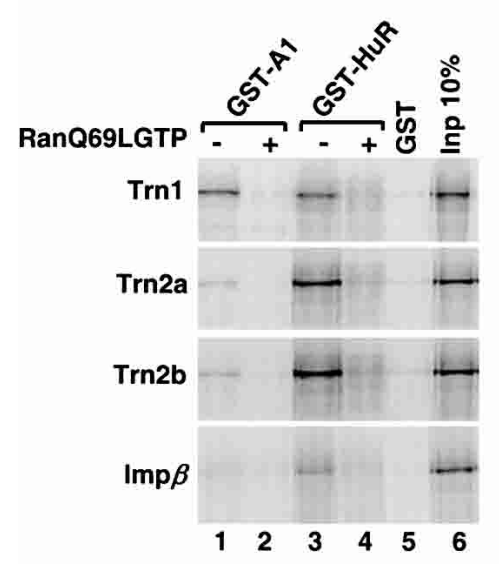

B

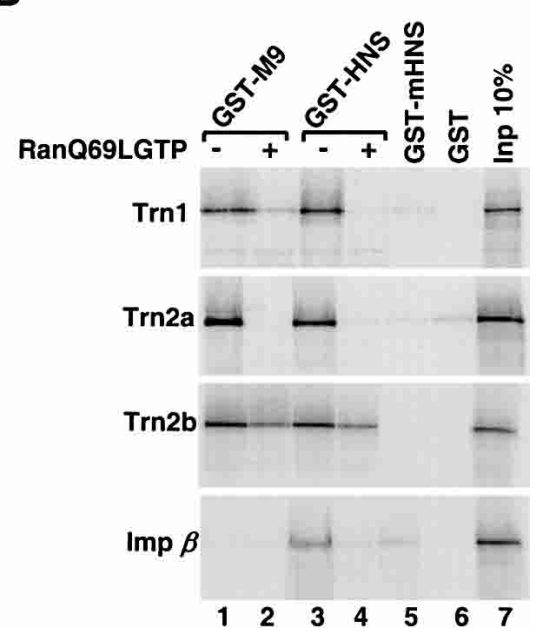

FIGURE 3. hnRNP Al and HuR interactions with transportins are dissociated by RanGTP. Glutathione Sepharose beads were precoated with GST-hnRNP A1, GST-HuR, or GST alone $(A)$ or with GST fusions of M9, HNS, mHNS (see Fig. 1A), or GST alone $(B)$ and assayed for binding to $\left[{ }^{35} \mathrm{~S}\right]$ methionine-labeled $\operatorname{Trn} 1, \operatorname{Trn} 2 \mathrm{a}, \operatorname{Trn} 2 \mathrm{~b}$, or $\operatorname{Imp} \beta$ in the presence $(+)$ or absence (-) of RanQ69LGTP. Lane 6 in $A$ and lane 7 in $B$ contain $10 \%$ of the $\left[{ }^{35} \mathrm{~S}\right]$ methioninelabeled protein used in adjacent lanes. Bound proteins were analyzed by SDS-PAGE followed by autoradiography, and the efficiency of GST-tagged protein binding to the beads was confirmed as in Figure 2 (data not shown).

(lanes 1-2, Trn2a panel) and between GST-HuR and $\left[{ }^{35}\right.$ S]Imp $\beta$ (lanes $3-4$, Imp $\beta$ panel) were detectably disrupted by RanQ69LGTP.

Thus, despite their sequence differences, both $\operatorname{Trn} 1$ and $\operatorname{Trn} 2 \mathrm{a} / \operatorname{Trn} 2 \mathrm{~b}$ appear to undergo conformational changes caused by the binding of RanGTP, leading to the partial or full dissociation of hnRNP A1 and HuR. This implies that all three transportins are potential import factors for hnRNP A1 and HuR. Even Imp $\beta$ might act as an import receptor for HuR because its binding to $\mathrm{HuR}$ is likewise sensitive to RanQ69LGTP.

\section{HNS of HuR and M9 of hnRNP A1 are sufficient for Ran-regulated binding to transportins}

The M9 shuttling sequence has been reported to be sufficient for hnRNP A1 binding to Trn1 (Pollard et al. 1996; Fridell et al. 1997) and the HNS of HuR has been observed to bind Trn2a (Gallouzi and Steitz 2001). We performed in vitro binding assays to establish whether M9 and HNS sequences are sufficient for interaction with the three transportins and whether these interactions are regulated by RanGTP, as is true of the full-length proteins. Figure $3 \mathrm{~B}$ shows that $\left[{ }^{35} \mathrm{~S}\right]$ methionine-labeled transportins do bind to GST-M9 (lane 1) or GST-HNS (lane 3), whereas $\left[{ }^{35} \mathrm{~S}\right] \mathrm{Imp}$ $\beta$ exhibits some affinity for GST-HNS (lane 3 ). In contrast, GST-mHNS (see sequence in Fig. 1A) did not detectably bind any of the transportins or Imp $\beta$ (lane 5). Thus, like P275 and M276 within the M9 consensus (Bogerd et al. 1999), P222 and M223 within HNS (see Fig. 1A) are essential amino acids for interaction with transportins. Note also that GST-M9 exhibits similar high affinity for $\left[{ }^{35} \mathrm{~S}\right] \operatorname{Trn} 2 \mathrm{a}$ and $\left[{ }^{35} \mathrm{~S}\right] \operatorname{Trn} 2 \mathrm{~b}$ (Fig. 3B), whereas full-length hnRNP A1 favored $\operatorname{Trn} 2 \mathrm{~b}$ over Trn $2 \mathrm{a}$ (Figs. 2, 3A). It is possible that recombinant GST-M9 does not present the M9 sequence in exactly the same way as full-length hnRNP A1.

Next, we tested the effect of RanQ69LGTP on interactions between the shuttling domains M9 or HNS and transportins. Figure $3 \mathrm{~B}$ reveals that binding of $\left[{ }^{35} \mathrm{~S}\right] \mathrm{Trn} 1$ or $\left[{ }^{35} \mathrm{~S}\right] \operatorname{Trn} 2 \mathrm{a}$ to GST-HNS or GST-M9 was severely diminished (sixfold to 13-fold; lanes 1-4), and interactions of $\left[{ }^{35} \mathrm{~S}\right] \operatorname{Trn} 2 \mathrm{~b}$ with GST-HNS or GST-M9 were impaired (twofold; lanes 1-4), when RanQ69LGTP was added. Also, the weak interaction between GST-HNS and Imp $\beta$ was disrupted by RanQ69LGTP (lanes 3-4).

Again, similar to the binding of the full-length proteins, GST-M9 or GSTHNS (Fig. 3, cf. A and B), interactions with Trn2b were less sensitive to RanQ69LGTP than those with Trn1 and Trn2a. This might result from either a lower affinity of Trn2b for RanGTP, a stronger interaction between Trn $2 b$ and hnRNP A1 or HuR compared with that of $\operatorname{Trn} 1$ or $\operatorname{Trn} 2 \mathrm{a}$, or a combination of both.

Previously, it was reported that $\operatorname{Trn} 2 \mathrm{~b}$ has lower affinity $\left(K_{\mathrm{d}} \sim 300 \mathrm{nM}\right)$ than Trn1 $\left(K_{\mathrm{d}} \sim 0.3 \mathrm{nM}\right)$ for RanGTP in a RanGAP assay, which supports the idea that Trn2b might be an export factor (Shamsher et al. 2002). However, another group (Güttinger et al. 2004) using the same assay has observed, instead, that $\operatorname{Trn} 1$ and $\operatorname{Trn} 2 \mathrm{~b}$ have the same affinity $\left(K_{\mathrm{d}} \sim 1 \mathrm{nM}\right)$ for RanGTP. In our experiments, the ability of RanQ69LGTP to dissociate $\left[{ }^{35} \mathrm{~S}\right] \mathrm{Trn} 2 \mathrm{~b}$ complexes with GST-M9 or GST-HNS was not increased if fourfold more RanQ69LGTP was added, if His-T7-tagged $\left[{ }^{35} \mathrm{~S}\right] \operatorname{Trn} 2 \mathrm{~b}$ instead of Flag-tagged $\left[{ }^{35} \mathrm{~S}\right] \operatorname{Trn} 2 \mathrm{~b}$ was used, or if reactions were performed at higher ionic strength $(200 \mathrm{mM}$ $\mathrm{KCl}$ instead of $110 \mathrm{mM} \mathrm{KOAc}$; data not shown). However, like Trn1 and Trn2a, Trn2b binds M9 or HNS efficiently in the absence of RanQ69LGTP at relatively high ionic strength (200 mM KCl; data not shown), indicating that Trn $2 \mathrm{~b}$ is an import receptor, and probably other factorssuch as competing nucleoporins or RNA - are needed to dissociate hnRNP A1 or HuR completely from Trn2b. Future experiments will be needed to test this hypothesis.

\section{M9 and HNS peptides compete for the nuclear import of recombinant hnRNP A1 and HuR in digitonin-permeabilized HeLa cells}

The results from our in vitro binding experiments indicate that transportins may act as import factors for HuR and 
hnRNP A1, in turn indicating that the nuclear import pathways for hnRNP A1 and HuR might at least partially overlap. To test this possibility, we carried out in vitro import assays in digitonin-permeabilized HeLa cells (Adam et al. 1990). First, to validate the system, we asked whether the transport of GST-hnRNP A1 and GST-HuR is stimulated by components present in HeLa S3 cytoplasmic extract. As shown in Figure 4A, both GST-HuR and GST-hnRNP A1 accumulate in the nucleus in the presence of HeLa cytosol and an energy-regenerating system (see Materials and Methods) at room temperature (panels 1-4). Under the same conditions, GST alone and GST-HuR-M2, which contains only the first two RNA-binding domains (RRMs) of HuR but lacks the HNS and the third RRM, are not imported (panels 9-12). If the reaction mixture was kept on ice, both GST-HuR and GST-hnRNP A1 were retained in the cytoplasm (panels 5-8). Note that GST-HuR and GSThnRNP A1 accumulate in the cytoplasm at $0^{\circ} \mathrm{C}$ (panels 5 and 7), probably because they efficiently bind mRNA.

We next tested the ability of synthetic HNS and M9 peptides to compete with GST-hnRNP Al and GST-HuR for import into the nucleus of digitonin-permeabilized HeLa cells. Previously, it was reported that a 200-fold molar excess (over the cargo) of NLS peptide competes successfully for the import of SV40 large T antigen but not of GST-M9 in this system (Pollard et al. 1996). As shown in Figure 4B, GST-hnRNP A1 (Fig. 4B, cf. panels 2 and 3 to panel 1) and GST-HuR (Fig. 4B, cf. panels 7 and 8 to panel 6) import was significantly reduced when a 300-fold excess of M9 or HNS peptide was used. In contrast, the same amounts of the mutant M9 peptide (mM9) or of the NLS peptide (see sequences in Fig. 1A and Materials and Methods) did not affect the import of GST-hnRNP A1 (Fig. 4B, cf. panels 1, 4,5 ) or GST-HuR (Fig. 4B, cf. panels 6, 9, and 10). In all our in vitro import experiments, GST-hnRNP A1 accumulation in the nucleus appeared more quantitative than that of GST-HuR because the cytoplasmic signal for GST-HuR was almost always higher than that for GST-hnRNP A1 (Fig. 4B, cf. panels 1 and 6). Consequently, the same level of M9 and HNS peptide had a greater effect on HuR than on hnRNP A1 import (Fig. 4B, cf. panels 2 and 3 to panels 7 and 8). Under these conditions, either GST-HuR import

A
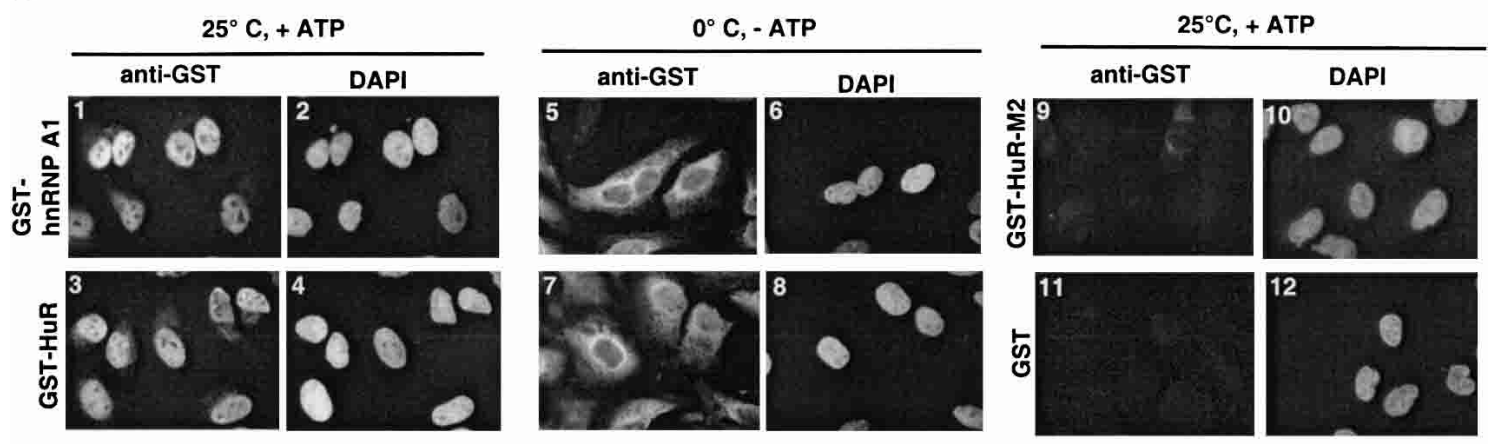

$\mathbf{B}$
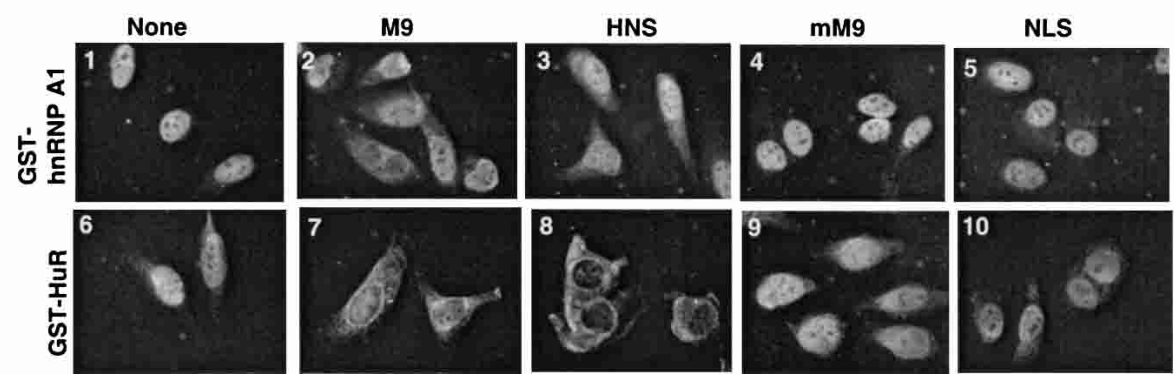

FIGURE 4. HNS and M9 peptides compete for the import of GST-hnRNP A1 and GST-HuR in digitonin-permeabilized HeLa cells. (A) Validation of the in vitro import assay using GST-hnRNP A1 and GST-HuR. Digitonin-permeabilized HeLa cells were incubated with HeLa cytosol along with GST-hnRNP A1 or GST-HuR, either at room temperature in the presence of ATP (anti-GST detection is shown in panels 1 and 3; DAPI nuclear staining in panels 2 and 4) or on ice in the absence of an energy regenerating system (anti-GST detection in panels 5 and 7; DAPI staining in panels 6 and 8). Panels 9 and 11 show the negative controls, GST-HuR-M2 (anti-GST detection in panel 9; DAPI staining in panel 10) and GST (anti-GST detection in panel 11; DAPI staining in panel 12), at room temperature in the presence of an energy-regenerating system. (B) HNS and M9 peptides compete for the import of GST-hnRNP A1 and GST-HuR. The effects of competing and control peptides (indicated on top) on in vitro import are presented for GST-hnRNP A1 in panels 2-5 and for GST-HuR in panels 7-10. The controls with no peptide are shown in panels 1 and 6. As in A, the negative controls GST-HuR-M2 and GST exhibited no nuclear accumulation (data not shown). The cellular localization of GST-tagged proteins was detected with anti-GST antibody (see Materials and Methods). In compiling the results from these assays, randomly picked fields containing 50-100 cells from several different experiments were evaluated by several observers. 
may be slower or its affinity for cytoplasmic mRNA higher compared with that of GST-hnRNP A1. In addition, although HuR and HNS possess weak affinity for Imp $\beta$ in in vitro binding assays (Figs. 2, 3), the NLS peptide does not compete for $\mathrm{HuR}$ import in the permeabilized cell assay (Fig. 4B, panel 10), supporting the argument that the Imp $\beta$ pathway is not a major pathway for HuR import.

In summary, experiments with M9 and HNS peptides in digitonin-permeabilized HeLa cells strengthen the conclusions from our in vitro binding results. Together, these data indicate that transportins are redundant import factors for hnRNP A1 and HuR. Simultaneous with our experiments, Güttinger et al. (2004) carried out in vitro import reconstitution assays with recombinant $\operatorname{Trn} 1$ and $\operatorname{Trn} 2 \mathrm{~b}$ and confirmed that both function as import factors for recombinant HuR in digitonin-permeabilized HeLa cells. Similar to our results based on cross-competition in in vitro import assays using cytoplasmic extract as a source of transport factors, Güttinger et al. (2004) also conclude that M9 and HNS are imported to the nucleus along redundant pathways.

Previously, the M9 and HNS peptides fused to a cellpermeable 16-amino-acid Antennapedia peptide (AP) were reported to compete with different mRNA export pathways: specifically, AP-HNS together with a CRM1 pathway inhibitor, AP-NES, abolished c-fos mRNA export and AP-M9 inhibited DHFR mRNA export (Gallouzi and Steitz 2001). Gallouzi and Steitz (2001) therefore suggested that Trn2 and CRM1 are both export receptors for c-fos mRNA via HuR as the adapter, and that $\operatorname{Trn} 1$ is responsible for DHFR mRNA export, via the adapter hnRNP A1. Unfortunately, the present data neither support the concept that $\operatorname{Trn} 1$ and Trn2 exclusively interact with hnRNP A1 and HuR, respectively, nor do they confirm the idea that transportins function as export factors. However, because transportins might act as import factors for several hnRNP proteins and for the main mRNA export factor TAP (for review, see Izaurralde 2002), transportins could have an indirect influence on mRNA export.

\section{What is the mechanism of hnRNP A1 and HuR shuttling?}

The directionality of Ran-dependent nucleocytoplasmic transport is determined by the GTPase Ran and its regulators, and probably to a lesser extent by the asymmetric distribution of certain nucleoporins (for review, see Mattaj and Englmeier 1998; Bednenko et al. 2003). However, the directionality provided by RanGTP is not necessarily absolute. Intriguingly, Becskei and Mattaj (2003) recently showed that CRM1-mediated Ran-dependent forward export is accompanied by Ran-independent but CRM1-mediated reverse export. According to this model, reverse movements of transport receptor-binding proteins through the NPC are avoided only when those proteins are actively retained by other factors on one or the other side of the
NPC. Thus, the shuttling of proteins containing the M9type bidirectional transport signal might simply reflect the imperfection of the RanGTP-provided directionality for transportin-dependent import. Nevertheless, we cannot exclude the possibility that there exist yet uncharacterized export factors for hnRNP A1 and HuR. For instance, HuR appears to use an alternative export pathway that involves its protein ligands, pp32 or APRIL, as adapters and CRM1 as the export receptor (Brennan and Steitz 2001; Gallouzi et al. 2001).

Yet other factors might influence hnRNP A1 and HuR nucleocytoplasmic transport. Various stress conditions and activation or inactivation of certain signal-transduction pathways seem to regulate both hnRNP A1 and HuR cytoplasmic levels (van der Houven van Oordt et al. 2000; Gallouzi et al. 2001; Wang et al. 2002). In addition, inhibition of RNA polymerase II transcription by actinomycin D or DRB relocalizes both M9- and HNS-containing proteins to the cytoplasm (Piñol-Roma and Dreyfuss 1991; Fan and Steitz 1998a; Nakielny et al. 1999). This suggests that modification of hnRNP A1 and HuR or their transport factors may determine the steady-state intracellular location of hnRNP A1 and HuR. Although hnRNP A1 is known to be both methylated (Kim et al. 1997) and phosphorylated (van der Houven van Oordt et al. 2000), no modifications have been reported within the M9 region. Only one modification, methylation of R217, has been found to take place in $\mathrm{HuR}$; this residue does reside within the HNS (Li et al. 2002). Whether these modifications influence the localization of hnRNP A1 and HuR remains to be studied.

\section{MATERIALS AND METHODS}

\section{Plasmids}

GST-Trn1 (Siomi et al. 1997), GST-Trn2a, myc-hnRNP A1 (Michael et al. 1995), and pCR-Imp $\beta$ clones were kind gifts from G. Dreyfuss (Univ. of Pennsylvania, Philadelphia); the GST-Trn2b clone (GST-Kap $\beta 2 B$; Shamsher et al. 2002) from A. Radu (Mount Sinai School of Medicine, New York); and the GST-Imp $\beta$ from Y. Yoneda (Osaka Univ., Osaka, Japan). GST-HuR and GST-HuRM2 are described in Gallouzi et al. (2000). GST-Trn1 Ran, GST$\operatorname{Trn} 2 \mathrm{a} \Delta$ Ran, and GST-Trn $2 \mathrm{~b} \Delta$ Ran were constructed by inserting PCR fragments corresponding to the C-terminal region of transportins (amino acids 493-890 of Trn1, amino acids 491-897 of Trn2a, amino acids $491-887$ of Trn2b) into the BamHI/NotI (GST-Trn1 $\Delta$ Ran ) or EcoRI/NotI (GST-Trn2a $\Delta$ Ran and GSTTrn2b $\Delta$ Ran) sites of pGEX-4T-1 (Amersham Pharmacia Biotech). GST-hnRNP Al was generated via insertion of PCR-generated hnRNP Al coding sequence into the pGEX-4T-1 vector (Amersham Pharmacia Biotech). Flag-Trn2a and Flag-Trn2b clones were made by moving the BamHI/XhoI fragments from the GST clones into a Flag-pCDNA3 vector that is a derivative of pcDNA3 (Invitrogen) containing a Flag tag. pET28c-Trn 1 was constructed by moving the BamHI/NotI fragment from GST-Trn1 into pET28c (Novagen). GST-M9 and GST-HNS contain PCR fragments corresponding to amino acids 263-294 of hnRNP A1 and amino acids 
201-240 of HuR inserted into the EcoRI/NotI sites of pGEX-4T-1 (Amersham Pharmacia Biotech). GST-mHNS (see Fig. 1A) was made using the QuickChange site-directed mutagenesis system (Stratagen). Resequencing of the Trn $2 \mathrm{~b}$ clone revealed a point mutation, R611C, in GST-Kapß2B (Shamsher et al. 2002). This mutation in the GST-Trn2b and Flag-Trn2b clones was reversed to correspond to the genomic sequence (NT 011295) using the QuickChange site-directed mutagenesis system (Stratagen), resulting in the GST-Trn2bC611R and Flag-Trn2bC611R clones. The GST-Trn2b protein encoded by the original GST-Kap $\beta 2 B$ (plasmid from A. Radu) was used for Figure 2, and Flag-Trn2bC611R for Figure 3. No significant differences in binding affinities for cargoes or RanGTP between Flag-Trn2b and Flag-Trn2bC611R were detected. pET28a-RanQ69L was made by insertion of PCRamplified sequence corresponding to RanQ69L from pQE32RanQ69L (gift from D. Görlich, University of Heidelberg, Germany) into the BamHI/XhoI sites of pET28a (Novagen).

\section{RT-PCR}

Total RNA from HeLa S3 and HEK293 cells was purified using Trizol reagent (Invitrogen) according to the manufacturer's instructions. cDNA for PCR reaction was prepared with Omniscript RT Kit (QIAGEN) according to the manufacturer's instructions; cDNA was synthesized on $2 \mu \mathrm{g}$ of total RNA, and $1 / 8$ of the reverse transcription reaction mix was used for the PCR reaction. Also, 10 pg of plasmid DNAs (pET28c-Trn1, Flag-Trn2a, Flag-Trn2b) was used as controls. For PCR, the following oligodeoxynucleotide primers were used: TR32, CCTTATATTCCTATGGTGTTGC ACCA; and TR33, GGGATTCACACTGATCATGGTACA; corresponding to Trn1 cDNA (NM153188) sequences 2233-2259 and 2451-2475, respectively; TR30, TTATGTGCAGATGGTCCTCAA; and TR34, TGCACCAAGGCCGGATGAA; corresponding to Trn2 cDNA (accession number AF019039) sequences 2224-2247 and 2369-2387, respectively.

\section{Recombinant proteins}

All proteins were expressed in BL21 (DE3) cells by induction with $0.2 \mathrm{M}$ IPTG overnight at $25^{\circ} \mathrm{C}$. GST-tagged proteins were purified essentially according to the manufacturer's instructions (Pharmacia Biotech), except that the bacterial lysate was supplemented with $1.5 \% \mathrm{~N}$-laurylsarcosine and sonicated four times for $15 \mathrm{sec}$ to solubilize GST-tagged proteins. To reduce protein degradation, 1 $\mathrm{mM}$ PMSF and $1 \times$ protease Inhibitors (Calbiochem) were included. Proteins were eluted from glutathione beads with $50 \mathrm{mM}$ Tris- $\mathrm{HCl}, 400 \mathrm{mM} \mathrm{NaCl}, 20 \mathrm{mM}$ glutathione, and $1 \mathrm{mM}$ DTT; dialyzed against a buffer containing $50 \mathrm{mM}$ Tris- $\mathrm{HCl}(\mathrm{pH} 8.0)$, $100 \mathrm{mM} \mathrm{NaCl}, 1 \mathrm{mM}$ DTT, and 10\% glycerol overnight; quickfrozen on dry ice; and stored at $-80^{\circ} \mathrm{C}$. His-RanQ69L was purified using TALON beads (Clontech), but otherwise essentially as described by Nakielny et al. (1999). Purified His-RanQ69L was dialyzed against $50 \mathrm{mM}$ Tris- $\mathrm{HCl}(\mathrm{pH} 7.5), 100 \mathrm{mM} \mathrm{NaCl}, 5 \mathrm{mM}$ $\mathrm{MgCl}_{2}, 1 \mathrm{mM} \mathrm{DTT}$, and $0.1 \mathrm{mM} \mathrm{GTP}$, and loaded with GTP in the presence of $1 \mathrm{mM}$ GTP for $1 \mathrm{~h}$ at room temperature. Excess GTP was removed by a Microcon (Millipore) filter device, in which the dialysis buffer was replaced with transport buffer TB (similar to Nakielny et al. 1999) containing 20 mM HEPES (pH 7.3), $110 \mathrm{mM}$ potassium acetate (KOAc), $5 \mathrm{mM}$ sodium acetate (NaOAc), $2 \mathrm{mM}$ magnesium acetate (MgOAc), $0.5 \mathrm{mM}$ EGTA, and $1 \mathrm{mM}$ DTT. RanQ69LGTP was quick-frozen on dry ice and stored at $-80^{\circ} \mathrm{C}$.

\section{Protein-binding assays}

To synthesize $\left[{ }^{35} \mathrm{~S}\right]$ methionine-labeled proteins by in vitro translation, the TnT T7 quick coupled transcription/translation system (Promega) was used according to the manufacturer's instructions. The following plasmids were used as templates: $\mathrm{pCRImp} \beta$ (Pollard et al. 1996), pET28c-Trn1, Flag-Trn2a, and Flag-Trn2bC611R.

In all binding experiments, $\sim 5 \mu \mathrm{g}$ of GST fusion proteins was loaded onto $40 \mu \mathrm{L}$ of glutathione Sepharose beads (Pharmacia Biotech) in TB buffer supplemented with $0.1 \%$ bovine serum albumine (BSA), $1 \mathrm{mM}$ PMSF, and $1 \times$ protease inhibitors (Calbiochem) for $1 \mathrm{~h}$ at $4^{\circ} \mathrm{C}$. After washing twice with $1 \mathrm{~mL}$ of $\mathrm{TB}$, the loaded beads were incubated for $2 \mathrm{~h}$ in $0.4 \mathrm{~mL}$ of TB plus $0.05 \%$ digitonin, $1 \mathrm{mM}$ PMSF, $1 \times$ protease inhibitors, $100 \mu \mathrm{g} / \mathrm{mL}$ of RNase A, and $0.1 \%$ BSA with either $50 \mu \mathrm{L}$ of nuclear extract (prepared as in Dignam et al. 1983; Fig. 2) or $4 \mu \mathrm{L}$ of $\left[{ }^{35} \mathrm{~S}\right] \mathrm{me}-$ thionine-labeled proteins (all other figures) at $4^{\circ} \mathrm{C}$, with $5 \mu \mathrm{g}$ of RanQ69L-GTP included as indicated. The beads were then washed four times with $0.5 \mathrm{~mL}$ of TB supplemented with $0.05 \%$ digitonin, boiled in SDS-PAGE sample buffer, and analyzed on SDS-PAGE followed by Western blot or autoradiography. The results presented in Figure 3 were quantified using PhosphorImager (Molecular Dynamics). For Western blots, monoclonal anti-hnRNP A1 4B10 (Piñol-Roma et al. 1988) or anti-HuR 3A2 (Gallouzi et al. 2000) was used diluted $1: 5000$ or 1:50,000, respectively (Fig. 2). For Figure 1C, the rabbit polyclonal anti-Trn2 serum was used at 1:2,000 dilution. HRP-conjugated goat anti-mouse IgG (Fig. 2) or goat anti-rabbit IgG (Fig. 1C; Pierce) was used at 1:5000 dilution as the secondary antibodies. The blots were developed using Western Lightning Reagent (PerkinElmer Life Sciences) and Chemidoc Imaging equipment (Bio-Rad).

Rabbit anti-Trn2 antibodies were raised by the Yale University Immunization Service against the Trn2-specific peptide (amino acids 344-357) CTLPHEAERPDGSED (synthesized by the Keck Facility at Yale University) conjugated to carrier using the Imject Maleimide Activated mcKLH kit (Pierce) and affinity-purified with SulphoLink Kit (Pierce).

\section{In vitro import assay and immunofluorescence}

HeLa S3 cytosolic extract (S100T), as the source of transport factors, was prepared by combining the Dignam et al. (1983) and Adam et al. (1990) protocols. Briefly, HeLa S3 spinner cells were resuspended in five packed cell volumes of cold buffer A $(10 \mathrm{mM}$ HEPES at pH 7.9, $1.5 \mathrm{mM} \mathrm{MgCl}_{2}, 1 \mathrm{mM}$ DTT, $10 \mathrm{mM} \mathrm{KCl}, 1 \mathrm{mM}$ PMSF). Cells were allowed to swell for $10 \mathrm{~min}$ on ice and lysed with eight strokes of a Kontes B pestle. Nuclei were removed by spinning at $1000 \mathrm{~g}$. To the supernatant, 0.11 volume of buffer B-100T (0.3 M HEPES at pH 7.3, 1.1 M KOAc, $30 \mathrm{mM} \mathrm{MgOAc})$ was added, followed by ultracentrifugation at 39,400 rpm for $1 \mathrm{~h}$ in a type $70 \mathrm{Ti}$ rotor. The clear fraction was then dialyzed against the TB buffer containing $10 \%$ glycerol, frozen in liquid nitrogen, and stored at $-80^{\circ} \mathrm{C}$.

In vitro import assays were performed essentially as in Adam et al. (1990). The HeLa cells grown 24 h on slides were washed twice with ice-cold TB buffer and permeabilized with $20 \mu \mathrm{g} / \mathrm{mL}$ digito- 
nin (Calbiochem). Permeabilized cells were washed three times with cold TB buffer and incubated 10 min on ice with TB plus $1 \times$ Protease Inhibitors (Calbiochem). Then, $25 \mu \mathrm{L}$ of transport mix (50\% of S100T in TB, supplemented with the energy regeneration system [0.5 mM GTP, $0.5 \mathrm{mM}$ ATP, $10 \mathrm{mM}$ creatine phosphate, $20 \mathrm{U} / \mathrm{mL}$ creatine kinase]) and $1 \mu \mathrm{M}$ GST-tagged recombinant import substrate were added, covered with parafilm, and incubated for $30 \mathrm{~min}$ at room temperature in a humidified box. As indicated, the following peptides (synthesized by the Keck Facility at Yale University) at $300 \mu \mathrm{M}$ were added to the import assay: NLS, CGGGPKKKRKVED; M9, NQSSNFGPMKGGNFGGRSSG PYGGGGQYFAKPRNQGGY (corresponding to amino acids 268306 of hnRNP A1); HNS, RRFGGPVHHQAQRFRFSPQ MGVDHMSGISGVNVPG (corresponding to amino acids 205238 of HuR), and mM9, FGNYNNFSSNQGAAKGGNFGARSSG PYGGGG (corresponding to amino acids 263-294, with the mutated amino acids underlined). After the import mixture was removed, cells were washed twice with $\mathrm{TB}$, and imported proteins were detected by immunofluorescence according to Fan and Steitz (1998a). Rabbit polyclonal anti-GST Z-5 (Santa Cruz Biotechnology) diluted 1:200 as primary and Texas red conjugated goat antirabbit IgG diluted 1:800 as secondary antibodies were used. For Figure 1E, affinity-purified rabbit polyclonal Trn2 antibody was used at dilution 1:10.

\section{ACKNOWLEDGMENTS}

We thank Gideon Dreyfuss, Aurelian Radu, Yoshihiro Yoneda, and Dirk Görlich for generous gifts of plasmids and antibodies; Woan-Yuh Tarn for help with the in vitro import assay; Jens Lykke-Andersen for making the GST-hnRNP Al clone; Eugene Mortison for making the GST-mHNS clone and protein; Jessica Babé for preparing the GST-Trn2a $\Delta$ Ran clone; and Mei-Di Shu for growing the HeLa S3 spinner cells. We are most grateful to Ulrike Kutay and Stephan Güttinger for sharing unpublished information and to Robin Lytle, Nicholas Conrad, Yingqun Huang, and Shobha Vasudevan for critical reading of the manuscript. This work was supported by grant CA 16038 from the NIH. J.A.S. is an investigator of the Howard Hughes Medical Institute.

The publication costs of this article were defrayed in part by payment of page charges. This article must therefore be hereby marked "advertisement" in accordance with 18 USC section 1734 solely to indicate this fact.

Received November 4, 2003; accepted December 22, 2003.

\section{REFERENCES}

Adam, S.A., Marr, R.S., and Gerace, L. 1990. Nuclear protein import in permeabilized mammalian cells requires soluble cytoplasmic factors. J. Cell Biol. 111: 807-816.

Bachi, A., Braun, I.C., Rodrigues, J.P., Pante, N., Ribbeck, K., von Kobbe, C., Kutay, U., Wilm, M., Görlich, D., Carmo-Fonseca, M., et al. 2000. The C-terminal domain of TAP interacts with the nuclear pore complex and promotes export of specific CTE-bearing RNA substrates. RNA 6: 136-158.

Becskei, A. and Mattaj, I.W. 2003. The strategy for coupling the RanGTP gradient to nuclear protein export. Proc. Natl. Acad. Sci. 100: 1717-1722.

Bednenko, J., Cingolani, G., and Gerace, L. 2003. Nucleocytoplasmic transport: Navigating the channel. Traffic 3: 127-135.
Bischoff, F.R., Klebe, C., Kretschmer, J., Wittinghofer, A., and Ponstingl, H. 1994. RanGAP1 induces GTPase activity of nuclear Rasrelated Ran. Proc. Natl. Acad. Sci. 91: 2587-2591.

Bogerd, H.P., Benson, R.E., Truant, R., Herold, A., Phingbodhipakkiya, M., and Cullen, B.R. 1999. Definition of a consensus transportin-specific nucleocytoplasmic transport signal. J. Biol. Chem. 274: 9771-9777.

Bonifaci, N., Moroianu, J., Radu, A., and Blobel, G. 1997. Karyopherin $\beta 2$ mediates nuclear import of a mRNA binding protein. Proc. Natl. Acad. Sci. 94: 5055-5060.

Brennan, C.M. and Steitz, J.A. 2001. HuR and mRNA stability. Cell. Mol. Life Sci. 58: 266-277.

Chook, Y.M. and Blobel, G. 1999. Structure of the nuclear transport complex karyopherin- 32 -RanGppNHp. Nature 399: 230-237.

. 2001. Karyopherins and nuclear import. Curr. Opin. Struct. Biol. 11: 703-715.

Chook, Y.M., Jung, A., Rosen, M.K., and Blobel, G. 2002. Uncoupling Kap $\beta 2$ substrate dissociation and Ran binding. Biochemistry 41: 6955-6966.

Dignam, J.D., Lebovitz, R.M., and Roeder, R.G. 1983. Accurate transcription initiation by RNA polymerase II in a soluble extract from isolated mammalian nuclei. Nucleic Acids Res. 11: 1475-1489.

Fan, X.C. and Steitz, J.A. 1998a. HNS, a nuclear-cytoplasmic shuttling sequence in HuR. Proc. Natl. Acad. Sci. 95: 15293-15298.

. 1998b. Overexpression of HuR, a nuclear-cytoplasmic shuttling protein, increases the in vivo stability of ARE-containing mRNAs. EMBO J. 17: 3448-3460.

Fridell, R.A., Truant, R., Thorne, L., Benson, R.E., and Cullen, B.R. 1997. Nuclear import of hnRNP A1 is mediated by a novel cellular cofactor related to karyopherin- $\beta$. J. Cell Sci. 110: 1325-1331.

Gallouzi, I.E. and Steitz, J.A. 2001. Delineation of mRNA export pathways by the use of cell-permeable peptides. Science 294: 1895-1901. Erratum. 2002. Science 296: 47.

Gallouzi, I. E., Brennan, C.M., Stenberg, M.G., Swanson, M.S., Eversole, A., Maizels, N., and Steitz, J.A. 2000. HuR binding to cytoplasmic mRNA is perturbed by heat shock. Proc. Natl. Acad. Sci. 97: 3073-3078. Correction. 2003. Proc. Natl. Acad. Sci. 100: 763.

Gallouzi, I.E., Brennan, C.M., and Steitz, J.A. 2001. Protein ligands mediate the CRM1-dependent export of HuR in response to heat shock. RNA 7: 1348-1361. Retraction in part. 2003. RNA 9: 1410.

Görlich, D. and Kutay, U. 1999. Transport between the cell nucleus and the cytoplasm. Annu. Rev. Cell Dev. Biol.15: 607-660.

Görlich, D., Pante, N., Kutay, U., Aebi, U., and Bischoff, F.R. 1996. Identification of different roles for RanGDP and RanGTP in nuclear protein import. EMBO J. 15: 5584-5594.

Güttinger, S., Mühlhäusser, P., Koller-Eichorn, R., Brennecke J., and Kutay, U. 2004. Transportin 2 functions as importin and mediates nuclear import of HuR. Proc. Natl. Acad. Sci. (in press).

Izaurralde, E. 2002. Nuclear export of messenger RNA. Results Probl. Cell Differ. 35: 133-150.

Izaurralde, E., Jarmolowski, A., Beisel, C., Mattaj, I.W., Dreyfuss, G., and Fischer, U. 1997a. A role for the M9 transport signal of hnRNP A1 in mRNA nuclear export. J. Cell Biol. 137: 27-35.

Izaurralde, E., Kutay, U., von Kobbe, C., Mattaj, I.W., and Görlich, D. 1997b. The asymmetric distribution of the constituents of the Ran system is essential for transport into and out of the nucleus. EMBO J. 16: 6535-6547.

Jäkel, S. and Görlich, D. 1998. Importin $\beta$, transportin, RanBP5 and RanBP7 mediate nuclear import of ribosomal proteins in mammalian cells. EMBO J. 17: 4491-4502.

Kim, S., Merrill, B.M., Rajpurohit, R., Kumar, A., Stone, K.L., Papov, V.V., Schneiders, J.M., Szer, W., Wilson, S.H., Paik, W.K., et al. 1997. Identification of $\mathrm{N}(\mathrm{G})$-methylarginine residues in human heterogeneous RNP protein A1: Phe/Gly-Gly-Gly-Arg-Gly-GlyGly/Phe is a preferred recognition motif. Biochemistry 36: 51855192.

Kuersten, S., Ohno, M., and Mattaj, I.W. 2001. Nucleocytoplasmic transport: Ran, $\beta$ and beyond. Trends. Cell Biol. 12: 497-503.

Li, H., Park, S., Kilburn, B., Jelinek, M.A., Henschen-Edman, A., 
Aswad, D.W., Stallcup, M.R., and Laird-Offringa, I.A. 2002. Lipopolysaccharide-induced methylation of HuR, an mRNA-stabilizing protein, by CARM1. Coactivator-associated arginine methyltransferase. J. Biol. Chem. 277: 44623-44630.

Mattaj, I.W. and Englmeier, L. 1998. Nucleocytoplasmic transport: The soluble phase. Annu. Rev. Biochem. 67: 265-306.

Michael, W.M., Choi, M., and Dreyfuss, G. 1995. A nuclear export signal in hnRNP A1: A signal-mediated, temperature-dependent nuclear protein export pathway. Cell 83: 415-422.

Nakielny, S., and Dreyfuss, G. 1999. Transport of proteins and RNAs in and out of the nucleus. Cell. 99: 677-690.

Nakielny, S., Siomi, M.C., Siomi, H., Michael, W.M., Pollard, V.W., and Dreyfuss, G. 1996. Transportin: Nuclear transport receptor of a novel nuclear protein import pathway. Exp. Cell Res. 229: 261266.

Nakielny, S., Shaikh, S., Burke, B., and Dreyfuss, G. 1999. Nup153 is an M9-containing mobile nucleoporin with a novel Ran-binding domain. EMBO J. 18: 1982-1995.

Piñol-Roma, S. and Dreyfuss, G. 1991. Transcription-dependent and transcription-independent nuclear transport of hnRNP proteins. Science 253: 312-314.

Piñol-Roma, S., Choi, Y.D, Matunis, M.J., and Dreyfuss, G. 1988. Immunopurification of heterogeneous nuclear ribonucleoprotein particles reveals an assortment of RNA-binding proteins. Genes \&
Dev. 2: 215-227. Erratum. 1988. Genes \& Dev. 2: 490.

Pollard, V.W., Michael, W.M., Nakielny, S., Siomi, M.C., Wang, F., and Dreyfuss, G. 1996. A novel receptor-mediated nuclear protein import pathway. Cell 86: 985-994.

Shamsher, M.K., Ploski, J., and Radu, A. 2002. Karyopherin $\beta$ 2B participates in mRNA export from the nucleus. Proc. Natl. Acad. Sci. 99: 14195-14199.

Siomi, H. and Dreyfuss, G. 1995. A nuclear localization domain in the hnRNP A1 protein. J. Cell Biol. 129: 551-560.

Siomi, M.C., Eder, P.S., Kataoka, N., Wan, L., Liu, Q., and Dreyfuss, G. 1997. Transportin-mediated nuclear import of heterogeneous nuclear RNP proteins. J. Cell Biol. 138: 1181-1192.

Truant, R., Kang, Y., and Cullen, B. 1999. The human Tap nuclear RNA export factor contains a novel transportin-dependent nuclear localization signal that lacks nuclear export signal function. J. Biol. Chem. 274: 32167-32171.

van der Houven van Oordt, W., Diaz-Meco, M.T., Lozano, J., Krainer, A.R., Moscat, J., and Caceres, J.F. 2000. The MKK(3/6)-p38-signaling cascade alters the subcellular distribution of hnRNP A1 and modulates alternative splicing regulation. J. Cell Biol. 149: 307-316.

Wang, W., Fan, J., Yang, X., Furer-Galban, S., Lopez de Silanes, I., von Kobbe, C., Guo, J., Georas, S.N., Foufelle, F., Hardie, D.G., et al. 2002. AMP-activated kinase regulates cytoplasmic HuR. Mol. Cell. Biol. 22: 3425-3436. 

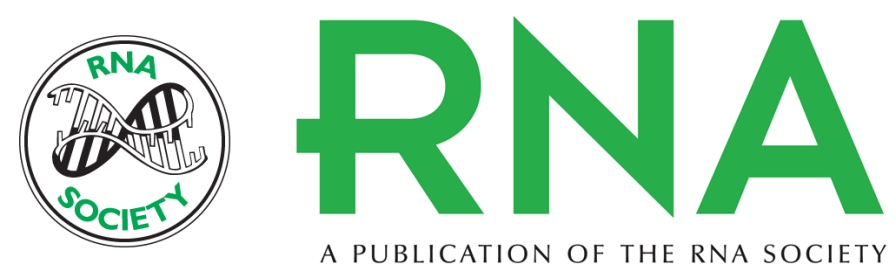

A PUBLICATION OF THE RNA SOCIETY

\section{Transportins 1 and 2 are redundant nuclear import factors for hnRNP A1 and HuR}

ANA REBANE, ALAR AAB and JOAN A. STEITZ

RNA 2004 10: 590-599

\section{References This article cites 40 articles, 21 of which can be accessed free at: http://rnajournal.cshlp.org/content/10/4/590.full.html\#ref-list-1}

\section{License}

Email Alerting Receive free email alerts when new articles cite this article - sign up in the box at the Service top right corner of the article or click here. 